Cuadernos del CILHA n 34-2021 | publicación continua

ISSN 1515-6125 | EISSN 1852-9615

https://revistas.uncu.edu.ar/ojs3/index.php/cilha

CC BY-NC 2.5 AR

Recibido: 10/05/2021 Aprobado: 08/06/2021 |

PP. 1-22

DOI: https://doi.org/10.48162/rev.34.006

\title{
Apuntes para una memoria feminista: hacia una literatura del nosotras
}

\author{
Notes for a feminist memory: towards a literature of us
}

Fernanda Laguna

Artista independiente Colectivo Ni Una Menos ferlaguna55@gmail.com

Argentina

Cecilia Palmeiro

iD https://orcid.org/0000-0002-3834-8825 Universidad Nacional de Tres de Febrero New York University in Buenos Aires

Colectivo Ni Una Menos ceciliapalmeiro@hotmail.com

Argentina

Resumen: Desde 2015, con el surgimiento del movimiento Ni Una Menos en la Argentina, los feminismos del mundo experimentan un proceso de masificación sin precedentes que permea todos los órdenes de la vida humana. En manifestaciones oceánicas de cientos de miles y hasta millones, los cuerpos sexuados y feminizados comenzamos a salir a las calles en todo el planeta para reclamar el fin de las violencias contra nosotras y nosotres, 
creando un movimiento transversal, horizontal e interseccional capaz de hacerle frente al neoliberalismo. Llamamos a este movimiento la marea feminista.

Este ensayo analiza las formas en que podemos aprehender esta experiencia en el sentido de hacer historia feminista del presente, a partir de la construcción del archivo-vivo "Mareadas en la marea: diario íntimo de una revolución feminista". Aquí proponemos siete hipótesis provisorias sobre la memoria feminista o herstory del presente de la marea feminista y esboza una teoría sobre una escritura del "nosotras".

Palabras clave: Herstory, Memoria colectiva, Archivo feminista, Ni una menos, Marea feminista.

Abstract: Since 2015, with the emergence of the Ni Una Menos (Not One Woman Less) in Argentina, feminisms around the world are experiencing an unprecedented process of popularization, that permeate every aspect of human life. In a wave of demonstrations of hundreds of thousands and even millions, gendered and feminized bodies started occupying the streets around the world to reclaim the end of violence against us, creating a transversal, horizontal and intersectional movement able to confront neoliberalism. We call this movement the global feminist tide.

This paper analyzes the forms in which we can apprehend this experience in the sense of making the feminist history of the present, based on the creation of our living-archive "High on the Tide: Diary of a Feminist Revolution". Here we propose seven provisory theses on contemporary feminist memory or herstory of the feminist tide as we outline a theory on collective writing.

Keywords: Herstory, Collective memory, Feminist archive, Ni una menos, Feminist tide.

\section{Introducción}

Que los feminismos disputan la historiografía patriarcal no es novedad. La Historia a secas, con mayúscula, como la Verdad, sin cuestionar, es siempre la narrativa de los ganadores, la falsa continuidad del triunfo de quienes han ganado las batallas: el patriarcado, el colonialismo y el capitalismo. La historia desde la perspectiva de les oprimides, ya lo decía Benjamin, es la de la discontinuidad: es la historia de los momentos de ruptura, en los que la historia podría haber tomado otro rumbo. Es la historia de los fracasos, y de los sueños incumplidos de cada era que exigen redención. Es por eso que una historiografía materialista y feminista se diferencia en método, en poética y en perspectiva del historicismo en el sentido de la continuidad y del progreso. 
Este texto abordará algunas reflexiones sobre la tarea de escribir una historia feminista de lo contemporáneo a partir de nuestra experiencia como curadoras del archivo-vivo "Mareadas en la marea: Diario íntimo de una revolución feminista". Este ensayo presentará el proyecto de memoria, la experiencia de la marea y a continuación, siete hipótesis sobre una historia feminista.

\section{Mareadas en la marea: Diario íntimo de una revolución feminista}

El proyecto "Mareadas en la marea" surgió a comienzos de 2017, al calor del armado del primer Paro Internacional de Mujeres (así se llamó en su primera edición, para cambiar luego a Paro Internacional Feminista en 2018 y después a Huelga General Feminista en 2019 y 2020). El pequeño archivo de nuestras acciones creativas realizadas con el colectivo Ni Una Menos desde 2015 ya comenzaba a irradiar su valor histórico y político cuando decidimos hacer una muestra en la galería Nora Fisch en Buenos Aires (Mayo-Julio 2017). Poco tiempo antes, habíamos comenzado a teorizar sobre el sujeto colectivo que se venía formando en los dos años de este nuevo feminismo masivo y popular: la marea global feminista ${ }^{1}$. Se trataba de establecer un archivo del presente más inmediato con los materiales de una experiencia vivida a toda velocidad y a puro vértigo, de un tiempo inflamado de intensidad revolucionaria y lleno de correspondencias con distintos pasados. De alguna manera, archivar para nosotras significa volver esa experiencia inteligible y reflexiva, para ser compartida con otres. $\mathrm{EI}$ archivo colectivo (y no la colección privada) de lo hecho colaborativamente, sin autoría individual, como puesta en común de saberes y poderes, como polinización de gérmenes de mundos por venir, no es sólo un diario de un proceso revolucionario hecho a partir de distintos lenguajes (verbal en los manifiestos y poemas, visual en los carteles, imágenes y videos, musical en las canciones que compusimos $)^{2}$, sino también un fragmento de la historia de nuestra amistad como un proceso de radicalización estética y política, de la amistad entre mujeres y cuerpos

\footnotetext{
${ }^{1}$ Para un mayor desarrollo del concepto de marea feminista, ver Palmeiro, C. (2019b).

2 Para un primer estudio del archivo, ver Palmeiro, C. (2019a).
}

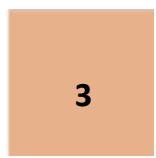


feminizados como vínculo revolucionario que genera sororidad e inteligencia colectiva, es decir, la naciente de una forma de creación de lo común ${ }^{3}$.

El archivo-vivo se transforma a cada minuto y sus materiales amplían y transforman sus significados. Por esas transformaciones el archivo ha tenido distintas manifestaciones en sus sucesivas exposiciones. Su segunda aparición, en Marzo de 2018 en la Universidad Nacional de General Sarmiento, se organizó con la idea de agitar el Paro con agrupaciones feministas del noroeste del Área Metropolitana de Buenos Aires, como el Frente de Mujeres de la Universidad Nacional de General Sarmiento, Hijas del Paro, Manija Feminista, etc. Su tercera exhibición, en la galería Campoli Presti de Londres, reunió en asamblea a mujeres de distintas agrupaciones como Women's Strike UK y Sisters Uncut así como generó las condiciones del surgimiento de Ni Una Menos UK. La tercera muestra se encuentra en exhibición en el Museo del Libro y de la Lengua de la Biblioteca Nacional Argentina desde el 10 de Marzo de 2020, como parte del evento la Kermés del Día Después, en alusión a la pastilla del día después tomando como centro la fecha del 9 de Marzo, Huelga General Feminista, y como celebración de los 5 años de Ni Una Menos. Desde Octubre de 2020 y hasta Enero de 2021, en su versión en inglés, la muestra se exhibe en el Institute for Contemporary Art de Virginia Commonwealth University, donde realizamos la cumbre feminista "Five Years of Feminist Tide" con representantes de organizaciones de 8 países centrales en nuestra Internacional Feminista.

A tres años de la creación del archivo, nos encontramos en el proceso de escritura del libro, propiamente el "Diario de una revolución feminista". Este ensayo es parte de ese proceso de escritura, como una reflexión teórica-metodológica de la construcción de esa memoria del presente.

\section{Herstory y marea feminista}

El origen de la palabra herstory remite a una identificación de los feminismos (de la llamada segunda ola, pero también del presente de la marea feminista) con un

\footnotetext{
${ }^{3}$ Con el colectivo Ni Una Menos hemos publicado un libro con los documentos y manifiestos escritos colectivamente. Ver: Colectivo Ni Una Menos (2018).
} 
feminismo originario sin ola: las millones de mujeres que fueron acusadas de brujería por sus saberes y sus poderes, que fueron perseguidas, torturadas y asesinadas en el mayor femicidio de la historia, la caza de brujas entre los siglos XIII y XVII. EI término herstory fue acuñado en 1970 por Robin Morgan en su antología Sisterhood is Powerful (1970) como parte del significado del acrónimo del colectivo W.I.T.C.H.: "The fluidity and wit of the witches is evident in the ever-changing acronym: the basic, original title was Women's International Terrorist Conspiracy from Hell [...] and the latest heard at this writing is Women Inspired to Commit Herstory" (p. 15).

Es la memoria de nuestras ancestras exigiendo justicia que reaparece cada vez que sube la marea. No es casualidad que la mayor investigación sobre la historia y la economía desde la perspectiva feminista sea contemporánea al colectivo WITCH y al feminismo radical: Calibán y la bruja. Mujeres, cuerpo y acumulación originaria ${ }^{4}$, de Silvia Federici.

Tampoco es casualidad que ese libro, que corrige la historia en sentido feminista, corrige a Foucault y a Marx, sea el texto central que inspiró al movimiento Ni Una Menos y su interpretación de la relación entre femicidio y acumulación de capital, entre violencias machistas y explotación y extracción, permitiendo un análisis materialista y feminista del neoliberalismo que sería fundamental en tanto arma crítica. Pero también aparece aquí el recurso a la magia en relación con la herstory, también formulada en este párrafo inicial como algo que se comete, como una transgresión, una desobediencia.

Desde 2015, la desobediencia feminista se ha vuelto marea que hace temblar la tierra. Es el sujeto colectivo que mujeres, lesbianas, travestis, trans y no binaries venimos componiendo a través de masivas movilizaciones en defensa de nuestras vidas y nuestros territorios. Se trata de un movimiento de fuerzas inaudito, de millones de cuerpos, que hace temblar la tierra entramando un nuevo internacionalismo, desde el sur y desde abajo.

\footnotetext{
${ }^{4}$ Aunque el libro fue publicado como tal en 2004, la investigación fue realizada en la década del 70 cuando Federici estudiaba su doctorado en SUNY. 
El grito colectivo Ni una menos, en sus diversas traducciones y tonalidades, Non Una di meno, Nehuma a Menos, irrumpió en el discurso institucional para denunciar el incremento en las tasas de femicidios y exponer la trama oculta de las violencias contra nosotras. Los femicidios, ahora desnaturalizados, comenzaron a percibirse como la punta del iceberg de una cadena de violencias cuya conexión se volvió evidente: la violencia física y sexual como las fuerzas de choque de las nuevas formas de explotación y de extracción a las que nos somete el neoliberalismo de alto impacto. La violencia aparece como la mayor fuerza productiva del momento, como señala Gago (2019) retomando a Mies (1986). La violencia física y sexual, verbal y simbólica, funcionan como soportes de la violencia económica y financiera que constituyen el corazón del patriarcado y su división sexual del trabajo y del capital. Las violencias contra nosotras no son un accidente: son parte constitutiva del régimen colonial-capitalista-patriarcal. El patriarcado como concepto crítico se instaló en los debates públicos a nivel continental, junto con su imbricación en la división internacional del trabajo. Así, los feminismos han visibilizado las intersecciones entre el dominio del régimen patriarcal y colonial: racismo y machismo pertenecen a un mismo orden, y deben ser desmontados a la par.

Surge así un amplio abanico de movimientos feministas que funcionan como vanguardia política de todas las luchas: por los territorios, por la salud, por la redistribución económica, por los trabajos de cuidado, por el acceso a la vivienda digna, por la educación. Es que la perspectiva feminista constituye la visión más radical sobre el capitalismo en su fase crítica, cuando las violencias y los despojos ponen en crisis la reproducción social y hasta la propia continuidad de la vida en el planeta.

Esta es la experiencia de la que queremos dar cuenta y potenciar a través del archivo: construir una herstory como un elemento más de la marea. Presentamos a continuación siete hipótesis sobre nuestra memoria íntima-colectiva.

\section{Algunas hipótesis sobre historiografía feminista}

Las olas, o en este caso la marea, suben cuando hay correspondencias históricas con el pasado, cuando sentimos el peso del pasado exigiendo memoria y justicia en el presente. Como las brujas inspiraron a la segunda ola, como la segunda ola y las brujas, 
las desaparecidas, las guerrilleras, las presas políticas, las que murieron anónimamente inspiran a la marea. No sólo consideramos historia los grandes movimientos sino también los pequeños, mínimos, personales, irrelevantes (desde una perspectiva historicista), los relatos orales y secretos: cualquier elemento del pasado puede ser un antecedente inspirador. Un chisme, un linaje, un objeto, un recuerdo vago, una imagen, una canción, un detalle. Al principio, las correspondencias se producen como revelación, no como un acto intencional; luego, una vez percibida la correspondencia, se le empieza a dar forma y a ahondar en qué es lo que se corresponde con qué, según cuestiones de estilo y afinidades personales. Pero entendemos que lo personal es político y es a la vez colectivo. La intuición de la correspondencia es un modo de conocer el presente.

Fue la lectura de las correspondencias la que en cada momento histórico agitó nuestras aguas. Una de las primeras entradas de nuestro diario es un ejemplo iluminador. Luego de la primera acción espectacular del Ni Una Menos (el debut de la marea el 3 de junio de 2015 con 300.000 personas en la calle) el colectivo estaba recién dividido y debilitado, sin saber bien para dónde ir. Entonces decidimos juntarnos a leer Calibán y la Bruja, que se volvió casi un texto sagrado de la herencia feminista. Ese mismo día, una revista golpista, Noticias, sacó una tapa con la recientemente devenida ex presidenta, Cristina Fernández, montada de medioevo quemándose en la hoguera rodeada de los hombres más poderosos del momento vestidos de monjes de la Inquisición. El título decía: "El Pacto para que Cristina no vuelva nunca más". En esa yuxtaposición temporal e imaginal estaba todo dicho: la nueva quema de brujas era la guerra contra las mujeres llevada a cabo por el neoliberalismo como una forma de asegurar la acumulación capitalista por desposesión. La fuerza de esta visión nos impulsó a organizar un escrache a la editorial Perfil como un aquelarre performativo. Este fue el flyer que repartimos y leímos en el escrache.

\section{AQUELARRE}

¿Con la tapa de una revista pretenden ponerle la tapa al caldero? Llaman al pacto asesino contra los cuerpos empoderados, contra la fiesta que se apodera de los cuerpos cuando en ellos se siente la potencia de hacer, de crear y de pelear. Llaman al pacto de la

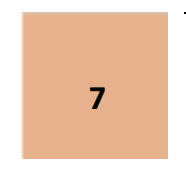


hoguera: pidiendo quemar al cuerpo femenino que osó plantar bandera y decir que cada unx de nosotrxs es su propio mariscal, a esa mujer que reconoce como capital la libertad de vivir como queremos, amar a quien queremos, ser quienes queremos ser. Quieren reponer el mando y la sumisión. Eso, ya lo sabemos, está en el origen del movimiento ejemplar del femicidio: castigar la autonomía y la asunción del propio deseo. Con una tapa se agita ese fantasma o esa amenaza para que se inscriba como miedo en nuestros cuerpos. iA la hoguera -gritan- con Ixs rebeldes, Ixs sabixs y los que construyen cuerpos potentes! Para poder saquear a gusto y con velocidad las riquezas sociales, para cercar y expropiar, desposeernos. Contra ese pacto, el nuestro: el aquelarre rebelde de las brujas, la algarabía alrededor del caldero, la paciente transmisión de un saber, la magia que impregna el cotidiano, el chamuyo que nos une y las maldiciones que les echamos.

Otra correspondencia central de nuestro archivo es el motor del primer Paro Nacional de Mujeres que organizamos a partir del femicidio por empalamiento de la joven Lucía Pérez en Mar del Plata el 8/10/16, yuxtapuesto con una feroz represión policial al movimiento de mujeres en Rosario, todo alrededor de la fecha clave del 12 de Octubre, día del comienzo de la conquista y colonización de América. La conjunción de tres fenómenos inquisitoriales en esa fecha: el empalamiento, la demonización de la víctima, el ensañamiento y persecución de las fuerzas armadas contra las mujeres en defensa de la Iglesia y del narcotráfico (el negocio del momento) fue elocuente. Esa correspondencia nos dio impulso para llevar la lucha a otro nivel, es decir, al nivel del boicot a la producción capitalista generando una medida de fuerza inaudita, que conmovió a América Latina entera que marchó con nosotras ese día histórico del 19 de Octubre de 2016. Ese fue nuestro Octubre revolucionario, cuando empezamos a hacer realidad la predicción que cantamos en las marchas de que "América Latina será toda feminista".

Las correspondencias históricas se dan por sí mismas: sólo es cuestión de estar atentas y poder leerlas. Como si la marea juntara esos fragmentos por el efecto de sus movimientos y produjera y visibilizara esas constelaciones que salen a la superficie. 
Para nosotras, la historia no son sólo los grandes hechos heroicos y estáticos, sino que está conformada por pequeños fragmentos, escenas, imágenes, sensaciones. La histórica jornada del 8 de Agosto de 2018, el día en el que dos millones de personas hacíamos una vigilia fuera del Congreso de la Nación donde se votaba (y se rechazaba) la ley en el Senado, nos despertamos con una sensación de fuerte presencia de nuestra abuela, a quien no llegamos a conocer, una mujer que tuvo doce hijes: a ella, y a sus contemporáneas, le debíamos la legalización del aborto. Ese pasado, así todos de los pasados que vuelven a ser perceptibles, no fue convocado intencionalmente: es su índice histórico, su correspondencia con el presente, lo que lo hace visible. Lo mismo sucedió cerca del día del quinto aniversario de Ni Una Menos, cuando una amiga casualmente posteó un poema nuestro escrito hace 20 años, cuando no podíamos imaginar que hoy estaríamos en medio de esa revolución que el poema anticipaba, como una profecía que adquiriría su pleno sentido veinte años después con un posteo. Incluso nosotras habíamos olvidado la existencia de ese poema hasta el posteo en cuestión.

Poder feminista, poder de las amas de casa.

Revolución matemática.

Las madres se animan a deshacer las leyes del hogar.

De a poco.

Una revolución a largo plazo y en soledad.

En vez de planchar camisas algunas las arrugarán,

Otras,

harán cosas que a mí no se me pueden ocurrir.

Una revolución no total, gradual y parcial.

Revolución en el plano de lo imaginable

y mientras no sea demasiado esfuerzo.

¿Por qué una re-volución?

Porque es re-acomodar las cosas, despejar la cabeza.

La que quiere puede utilizar el sistema de shock y la que no, 
el sistema de postergación, de huida o otros.

¿Por qué re-volución matemática?

Porque los números son la voz de la materia en general.

Podemos dedicarle la re-volución a:

Duchamp, el Bosco, Leonardo, Giotto, Jane Bowls, Santa teresa, Santa Clara, tantas brujas que quedaron sin nombres

y a las artistas que crearon ciudades acomodando vasos en la alacena.

Creo en el poder de la mente que puede

transformar, transportar y desmaterializar objetos.

Un simple movimierto re-volutivo de un plato puede

TTD objetos en otras áreas del planeta.

Creo y te invito a creer, por último,

AMIGA/O

en el poder reconstituyente de la autoestima

en el poder de la somatización, el mimetismo, la simbiosis, y la superstición.

¡Démosle un lugar a la fantasía!

Nosotras que logramos ver a los seres de baja resolución con lo lateral del ojo.

* hacer lo que una tiene ganas de hacer. $(2013$, p. 25)

Estas temporalidades que se convocan mutuamente forman el pliegue de una ola en el movimiento de la marea. Pasado, presente y futuro no están en línea de tiempo estática sino que el tiempo es pura fluctuación en la medida en que las correspondencias producen saltos en el tiempo.

En su libro Is the rectum a grave? And Other Essays, Leo Bersani formula una teoría de las correspondencias de formas como una relacionalidad universal, una especie de mismidad no identitaria que conecta las afinidades entre los seres y las cosas del mundo. Es "un régimen ontológico de correspondencias en el cual la discreción de todas las cosas (incluyendo a los sujetos humanos) está substituida, no por fusiones universales, sino por la continuación de las cosas en otra parte [...] El deseo sería el reconocimiento afectivo de algo así como nuestra deuda a todas aquellas formas de ser que relacionalmente definen y activan nuestro ser. El deseo moviliza correspondencias del ser" (traducción nuestra, p. 89). 
Si aceptamos la hipótesis de Bersani, podemos aventurar que las correspondencias producen acuerpamientos intertodo (no solo entre humanos o seres vivos), como "una solidaridad universal del ser", cuando los ritmos íntimos en cuanto frecuencias vibratorias están acompasados, fluyendo. Cuando se producen estas correspondencias es cuando ocurre la magia.

La historiografía feminista depende de un tipo particular de memoria que es afectiva, íntima y colectiva a la vez. Es una memoria voluntaria e involuntaria y ancestral por su carácter colectivo. Escribir juntas es permitir que el pasado se nos revele y se nos resignifique como acto colectivo a partir de los distintos tipos de memoria: los sueños, la memoria del cuerpo (como en los casos de abuso y trauma). Se produce así la validación de otras memorias, como las que se hacen en las terapias de sanación: constelaciones, regresiones, registros akáshicos, hipnosis, memoria celular, baños de gong, tarot; en estas prácticas es más importante el pasado que el futuro y el conocimiento del presente es como un viaje en el tiempo. Ese es el modo mágico en que las brujas se relacionan con el tiempo. La historia feminista puede formularse entonces como práctica de sanación en vez de redención como lo proponía Benjamin. Lo que importa no es redimir el pasado sino sanarlo a través de prácticas en el presente que se ve así recuperado. La memoria feminista, por su carácter afectivo e intuitivo, da lugar a lo incomprensible, lo indefinido, lo que no entra en la serie lineal causaconsecuencia.

La memoria feminista elabora subjetividad colectiva contra la individualidad privatizada propia de la subjetividad neoliberal. Se trata de una escritura del nosotras y no del yo. La literatura del yo, el "yolleo" como lo llama Daniel Link (2009), aparece fuertemente en la década del 2000 en la Argentina en relación con la emergencia de las editoriales independientes (en particular Belleza y Felicidad) y la política queer, en un contexto de conservadurismo misógino editorial y de crisis general del neoliberalismo que afectaba particularmente el mercado de libros. Las lenguas de las locas ${ }^{5}$ que surgían en ese cruce daban cuenta de procesos de singularización y devenires a tono con la retórica de la diferencia de lo queer, la cultura autogestiva y el comienzo "democratizante" de las redes sociales. Se trataba de establecer códigos de ruptura liberadores. Veinte años después, en un mundo totalmente fragmentado por décadas

\footnotetext{
${ }^{5}$ Ver Lopez Seoane, M. y Palmeiro, C. (Junio 2015).
} 
de neoliberalismo surge la necesidad desde los feminismos de la creación de lo común, los territorios comunes: las calles, los textos, los murales, las huertas. En nuestro caso particular, este proceso empieza hace cinco años con el grito colectivo Ni Una Menos y la escritura de manifiestos reunidos en el libro Amistad Política + Inteligencia Colectiva. Un ejemplo conmovedor es la fundación y el desarrollo de la Jineología, la ciencia de las mujeres kurdas, construida colectivamente y en proceso asambleario. Esos modos de construcción de una voz colectiva son formas de producir acuerpamiento.

Frente a los procesos de privatización de todos los aspectos de la vida del neoliberalismo y de "individuación como abstracción masculina universalizante", oponemos el acuerpamiento, como señala nuestra compañera del colectivo Ni Una Menos, Verónica Gago, en su libro La potencia feminista, o el deseo de cambiarlo todo (2019). En palabras de la Red de Sanadoras Ancestrales del Feminismo Comunitario Territorial desde Iximulew, Guatemala:

acuerparnos es decir, estar, sentir, accionar y juntarnos en la plena conciencia para defender de manera colectiva nuestros cuerpos y la tierra, por ancestralidad pero también por derechos. Según la Red, el acuerpamiento puede hacerse de varias formas: desde el cuerpo, abrazando, estando cerca de quien ha sufrido; desde lo personal, escuchando para que esa persona pueda contar lo que ha vivido; con otros procesos de sanación como ceremonias ${ }^{6}$.

El acuerpamiento también puede producirse a través de la escritura y la memoria colectiva en su capacidad de "combate, [...] cuidado, sanación, defensa y fortalecimiento" (Gago, p. 111). El acuerpamiento no es una sumatoria de identidades individuales sino la creación de un cuerpo/inteligencia colectivo. Una de las características de la inteligencia colectiva es que puede ser contradictoria y permitirse todo lo que está fuera de la razón instrumental occidental. Su pensamiento está en movimiento para todas las direcciones, no es lineal ni es progresivo, sino que se mueve con forma de espiral.

\footnotetext{
${ }^{6}$ Disponible en https://pbi-guatemala.org/es/qui\%C3\%A9n-acompa\%C3\%B1amos/tzkat-red-de-sanadorasancestrales-del-feminismo-comunitario-desde-ixmulew-

0\#: :text=TZK\%60AT*\%2C\%20Red\%20de,sostenerse\%20mutuamente\%20frente\%20al\%20riesgo
}

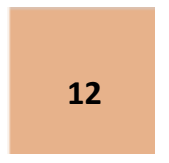

Cuadernos del CILHA n $34-2021$

ISSN 1515-6125 | EISSN 1852-9615 
La memoria afectiva es intuitiva, y la intuición o el "saber-de-lo-vivo", como lo llama Suely Rolnik en su libro Esferas de la insurrección. Notas para descolonizar el inconsciente (2019), es una forma válida de saber ya que aporta un tipo de información mnemónica sensorial por resonancia, que está en la base de nuestro criterio curatorial del archivo y del montaje de la muestra. Se trata de liberar la percepción de su reducción a la razón utilitaria para expandir los sentidos.

La memoria se produce en la elección de los artefactos y en el armado de constelaciones entre objetos, que disparan vectores de fuerza entre sí y hacia nuestros cuerpos. La memoria se compone en los espacios entre los objetos, integrados en un campo de fuerzas. De ese "entre" los artefactos surge la experiencia perceptiva de la constelación y el relato. Encontramos allí una tensión entre la memoria pura (la sensación que asalta a la consciencia, fragmentaria) y el relato que construye la conciencia alrededor de eso. En ello consisten las dos instancias del proyecto: lo sensorial-sinestésico y lo verbal/sonoro (narrativo), con el propósito de compartir intensidades. Queremos que la gente que ve la muestra o lee el texto pueda reverberar con esas emociones vitales y afectar sus cuerpos para generar nuevos acuerpamientos. En palabras de Suely Rolnik:

En este plano no existe distinción entre sujeto cognoscente y objeto exterior: [...] el mundo vive efectivamente en nuestro cuerpo y produce en este gérmenes de otros mundos en estado virtual. La pulsación de esos mundos larvarios en nuestro cuerpo nos lanza a un estado de extrañeza. (p. 47)

En la selección de los objetos ponemos lo que menos intención histórica tenía (objetos menores, objetos que no tienen un claro interés histórico -la foto de una rodilla lastimada, cuando no importaba el dolor porque lo que sentíamos era mucho más fuerte)- - La intensidad se hace perceptible en la tensión entre el acontecimiento de la mega marcha y el detalle de la rodilla lastimada.

La Historia está compuesta por una narración de hechos trascendentes sin atmósfera, entrando directo en el canon de una memoria oficial, borrando lo humano de las acciones (historia en el sentido hegeliano). Nuestra memoria integra hechos menores, detalles configuradores de la intensidad, e historias micro. 
La forma épica que le corresponde a la memoria de la intuición es el chisme anecdótico como género literario menor y de la oralidad. Su lengua es la lengua de las locas. EI chisme es una memoria oral vaga, como un ejercicio ficcional. Lo importante del chisme es lo poético y lo jugoso. Su función poética prioriza el cómo sobre el qué. La poesía es el único arte anticapitalista que da más de lo que recibe en el intercambio compraventa. Siempre guarda un misterio, algo inaprehensible por fuera de lo informativo. La poesía es el lenguaje del arte, lo más sublime de todo arte, lo que expresa más allá del lenguaje y la significación. Tomamos la poesía para crear un nuevo lenguaje político con la función social de agitar, de crear lo nuevo y transmitir energías de desobediencia e insurrección.

El chisme da el tono a las lenguas de las locas en su capacidad narrativa como tráfico de información de trinchera, fundamental para la supervivencia y para la diversión. El chisme es parte de la lógica del secreto, de las filtraciones, de las ramificaciones; se cuenta en un momento de confianza, genera amistad, genera conectividad y confidencialidad. Genera, establece y consolida sororidad: siempre requiere un pacto de silencio aunque ya se sabe que va a ser roto. El chisme es como un don que se comparte, generando relación de afectos.

Es una información íntima y marginal que se vuelve relevante por la prohibición de contarlo y la transgresión que sugiere (romper un pacto de silencio y establecer uno nuevo). La expresión que usamos para resumir es: "Que no salga de Latinoamérica". Mientras más conexiones tengamos con el chisme, más jugoso es por la tensión que genera entre lo público y lo secreto. Es el género por antonomasia de la intimidad entre mujeres: su reino es la peluquería, la depiladora, la cocina, el baño, los pasillos, las bambalinas. El chisme es un modo de romper el silencio al que somos confinadas y de generar complicidad, y alianzas insólitas. Establece la posibilidad de decir cualquier cosa o todo.

Sus temas son los tabúes: la sexualidad, el cuerpo, las transgresiones. Hacer público un chisme es una denuncia. Contar un chisme iguala, desarma jerarquías sociales, es un acto emancipador por la transgresión: un ejercicio de libertad, derecho a la poesía y justicia poética. Es una forma de arte: el arte de chusmear; en él, descripción y narración 
son igualmente importantes. El chisme nunca idéntico a sí mismo: niega el principio lógico de identidad.

Es el under de la información y por eso nuestra historia, no autorizada, menor, es como un chisme en el sentido de que se adelanta a la información: es primicia y vanguardia, lo menos importante pasa a ser lo más importante, es potencialmente un peligro. EI peligro es que se salga de las pistas, de su circuito que son las lenguas de las locas a las que empodera. El chisme se potencia con las voces y con el agregado de detalles, con el armado coral. Tiene una intención didáctica y de autodefensa como contrabando de saberes.

En la memoria feminista importa más la función expresiva de los artefactos que la informativa. El objeto de poder despierta involuntariamente memorias colectivas imprevistas. Su pedagogía subversiva es el humor como juego desacralizador, su afecto es la risa. El humor, como efecto del juego, devuelve aquello que fue sacralizado (es decir, separado en un panteón) al plano de lo mundano.

"El juego libera y aparta a la humanidad de la esfera de lo sagrado", sostiene Agamben en Profanaciones. Lo sacralizado en la religión o en el museo se ve sometido a un proceso de comercialización y privatización para generar acumulación de riqueza y de poder. Contrariamente, el juego como ritual profano expresa una potencia humanizante, iconoclasta, integradora y divertida. La risa desacralizadora es un efecto de esta memoria, poder reírnos con nuestras acciones. Hay una intencionalidad de lo cómico: abre una nueva mirada sobre las cosas, una especie de deconstrucción, de extrañamiento, permite una nueva percepción desautomatizada. Reírse de algo es ver su aspecto menos sagrado y solemne es un acto liberador. Se gesta así, desde esta forma de hacer historia, un feminismo del placer y del disfrute por lo emancipatorio de las acciones que producen la risa, tanto en el presente de la acción (pasarla bien durante las actividades) como en el recuerdo. La risa abre al pasado y lo puede modificar en el sentido de la felicidad.

Algunas de las acciones íntimas-públicas y micropolíticas que guardamos en el archivo y que iluminan esta perspectiva son: el \#Orgasmatón (Marzo 2018), la Apostasía Feminista para Decidir (Septiembre 2018) y el Telo Lésbico (Marzo 2019). 


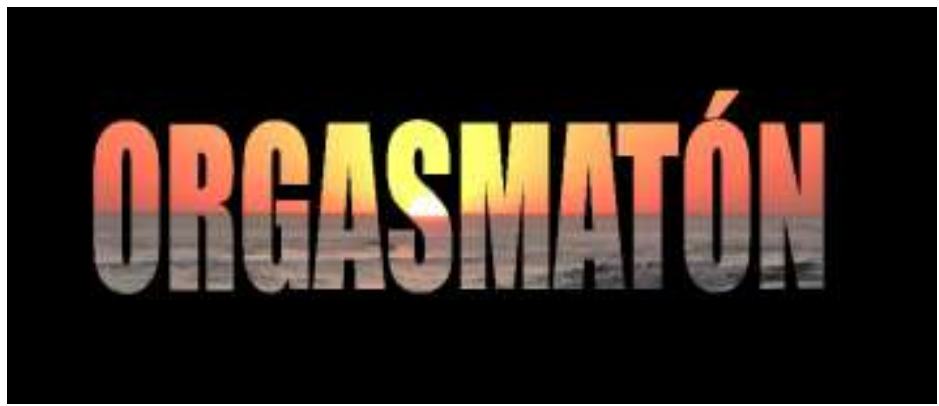

Fotograma de Ni una menos (2018, 6 de marzo). Orgasmaton. Acabamos con el patriarcado. [video]. Youtube. https://www.youtube.com/watch?v=YBtXaM67h g

El \#Orgasmatón fue una convocatoria a una acción del orden de la magia sexual: un llamamiento a proporcionarse un orgasmo a las 0 hs del día 8 de Marzo para sensualizar el Paro Internacional Feminista. La campaña constaba de 3 videos y textos poéticos que relacionaban el orgasmo con el mundo por venir que se anunciaba en el paro, y, por lo tanto, con el mundo patriarcal que comienza a caer, o un fin de un mundo?.

La Apostasía Colectiva Feminista para Decidir fue una acción organizada como respuesta al lobby de las Iglesias contra la legalización del aborto en 2018. Para esa acción produjimos la fachada de una iglesia en llamas literalizando la mítica cita de Piotr Kropotkin: "La única iglesia que ilumina es la que arde". En esa fachada, hecha de cartón pintado, la gente se sacaba fotos luego de entregar su trámite de apostasía, donde también se entregaban estampitas profanas.

7 Ver: https://www.facebook.com/watch/?ref=search\&v=780472202143964\&external log id=98da20aacd0c-4c53-933c-4e39be0c8b92\&q=ni\%20una\%20menos\%20orgasmaton 
Fernanda Laguna y Cecilia Palmeiro

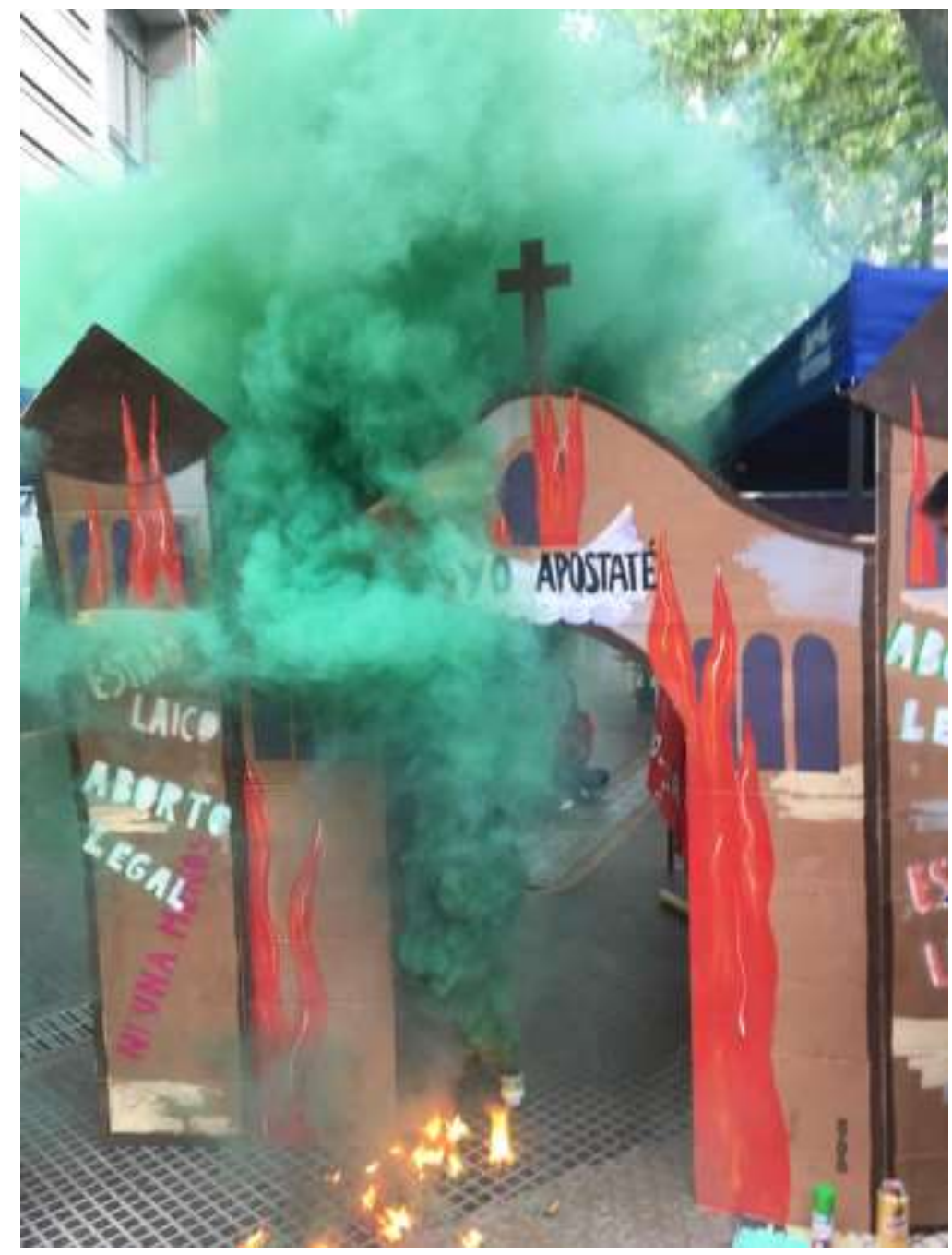

Fotógrafa: Cecilia Palmeiro. 2017. Archivo Mareadas en la marea.

El Telo Lésbico es una carpa al estilo teepee, pintada a mano colectivamente con imágenes y consignas feministas, instalada en la Plaza del Congreso en la previa al Paro Internacional Feminista (en el día de la visibilidad lésbica) para que las compañeras

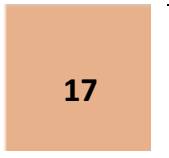

Cuadernos del CILHA n 34-2021

ISSN 1515-6125 | EISSN 1852-9615

CC BY-NC 2.5 AR

https://revistas.uncu.edu.ar/ojs3/index.php/cilha 
pudieran tener sexo como parte de la celebración, erotizando la política y politizando el placer en una protesta sexual.

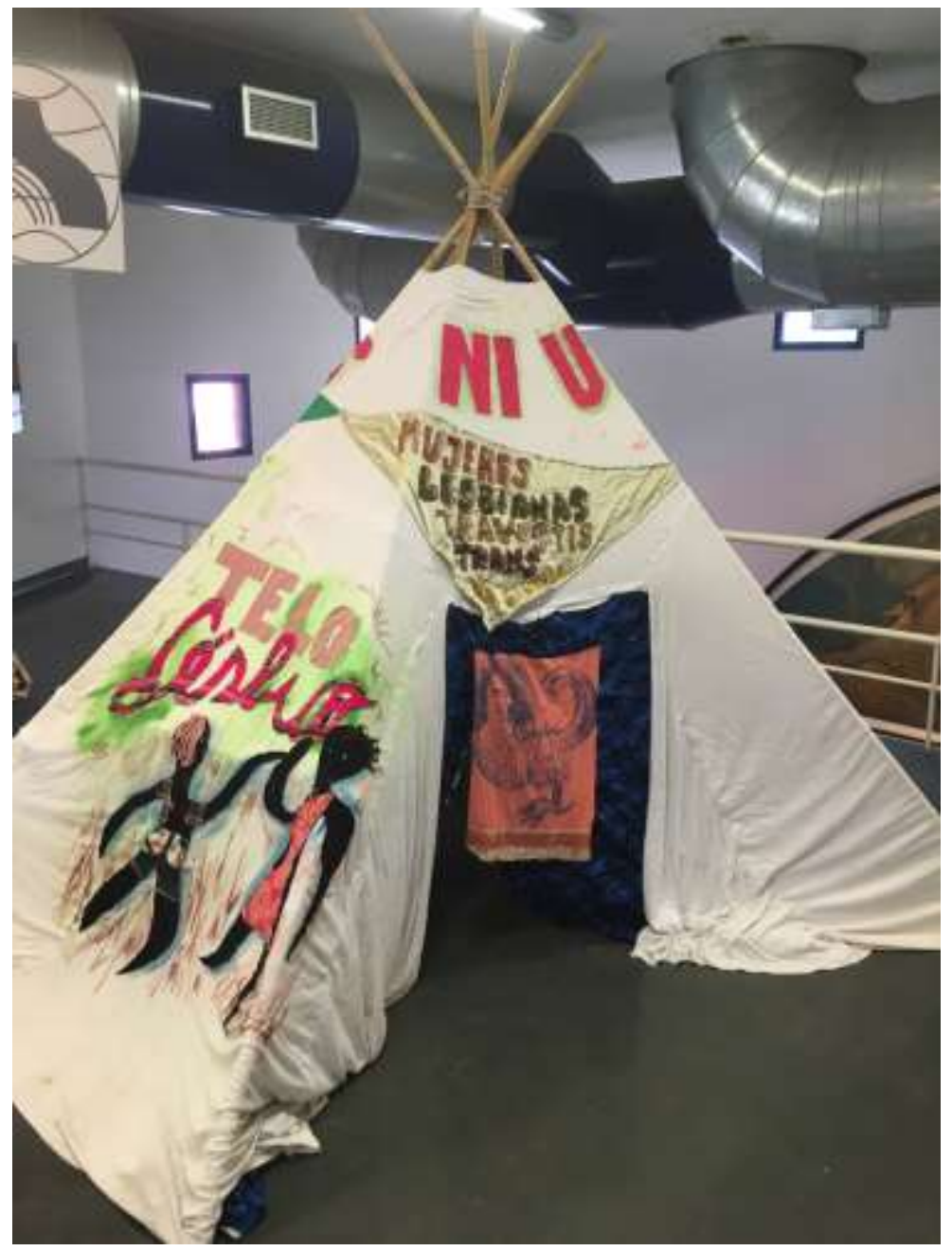

Fotógrafa: Cecilia Palmeiro. 2017. Archivo Mareadas en la marea.

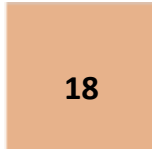

Cuadernos del CILHA n $34-2021$

ISSN 1515-6125 | EISSN 1852-9615

CC BY-NC 2.5 AR

https://revistas.uncu.edu.ar/ojs3/index.php/cilha 
Cuando observamos, por ejemplo, la iglesia de la apostasía, no vemos solo el femicidio eclesiástico, sino también la felicidad del derrumbe a través de nuestra rebeldía. El humor es una herramienta de lucha, una estrategia, una fuente de energía y de cuidado de la fuerza. Permite lo experimental, el riesgo y la sorpresa. Todas estas sensaciones intensifican la percepción y la memoria afectiva, como un salto cualitativo entre planos expresivos. En la percepción de la memoria, estos objetos a través de la risa se reactualizan y adquieren nueva fuerza.

Nuestra historia feminista es micro relato de anécdotas al estilo chisme de lo recién vivido como historia de lo contemporáneo, desde el presente expandido, que convoca imágenes de distintos momentos del pasado. A cada presente corresponden varios (y no uno) momentos del pasado: nuestras imágenes no son dialécticas sino, podríamos decirles, multilécticas. La dialéctica es propia de un pensamiento binario y, por lo tanto, jerarquizante; por eso beneficia a los que están por encima en la división jerárquica (hombre-mujer, cultura-naturaleza, mente-cuerpo, etc.). En la imagen de la marea, los pasados serían como las olas, y lo que traen las olas: sus fuerzas son simultáneas al presente. La relación entre presente y pasado es cambiante $\mathrm{y}$ depende de los movimientos de marea, las subidas, las bajadas. Son muchos los pasados que exigen sanación, sin jerarquías (las abuelas, las desaparecidas, las brujas, las sufragistas, etc.).

Walter Benjamin decía que las luchas tomaban su fuerza de las imágenes de opresión del pasado y no de las imágenes idealizadas del futuro, aunque podamos de alguna manera sentir al nivel de los cuerpos (y no mentalmente) los gérmenes de los mundos posibles por venir, que también son parte de la marea, sin construirlos como imágenes idealizadas sino como prácticas creadoras de mundos en los que queremos vivir. En la intensidad del tiempo revolucionario aparecen todos los tiempos juntos: correspondencias con los pasados para crear los futuros del mundo en el que queremos vivir. 


\section{Conclusión}

Cuando decimos que al feminismo lo mueve el deseo de cambiarlo todo, hablamos de poner en práctica modos de transformación que van desde el conocimiento hasta la organización política y social y los cuidados. Una sociedad patriarcal depende de una episteme patriarcal y una subjetividad patriarcal. Con nuestro activismo intentamos hacer una micropolítica transformadora a nivel subjetivo y empezar a producir nuevos tipos de conocimiento y formas de organización y comunidad feministas. Esos tipos de conocimiento tendrían la capacidad de sanar el mundo desde la perspectiva de cuerpoterritorio.

Entendemos estas prácticas como antídotos contra el neoliberalismo, frente a sus violencias, oponemos cuidados.

La historia patriarcal es violencia epistémica: justifica nuestra subordinación en el presente a través de un borramiento de nuestro pasado. Desde esta perspectiva no somos sujetas de la historia, y por lo tanto no merecemos ser sujetas de deseo y de derecho en el presente.

La historia feminista es diferente de la Historia que es obviamente patriarcal en sus rasgos constitutivos. Frente a la narración de los grandes hechos creados por los grandes genios (los padres fundadores), retomamos las historias pequeñas, trayectorias personales, y lo marginalizado para poder recuperar la historia de las mujeres que fueron borradas, ninguneadas, silenciadas de la historia. Como una arqueología de nuestras existencias invisibilizadas y desjerarquizadas. La historia patriarcal al borrar nuestras existencias borra las violencias a las que somos sometidas: la imagen es la de una fosa común. Si no importamos en la historia, es que nuestras vidas no importan y nuestros cuerpos son explotables y descartables. En ese sentido, nos oponemos al criterio de calidad estética racista, clasista y patriarcal porque es un criterio formulado para excluirnos. Lo mismo podemos decir de la autoridad y las formas de legitimación. A la pregunta de ¿Quiénes somos nosotras para hacer historia?, le corresponde la increpación de una de las centrales obreras a la hora de organizar nuestra primera huelga general: ¿Quiénes son ustedes para organizar un paro? Tanto nuestra historia como nuestras acciones están al alcance de cualquiera que pueda retrucar ¿Por qué no? 
Nuestra fuerza viene del acumulado histórico y político de nuestras propias luchas y de nuestras genealogías: si nosotras dos nos atrevemos a hacer historia, es porque nos atrevimos a hacer un paro. En ambos casos, lo hicimos porque pudimos conectarnos con la fuerza de todas las que vinieron antes. Nuestra historia es justicia y autodefensa.

Es un archivo de la devolución a la vida de la potencia creadora expropiada en el mundo del arte. No buscamos la originalidad ni la novedad en el sentido del arte autónomo y del consumo, ni la gloria de la autoría, sino un modo de agitar la marea en el presente y proyectarla hacia el futuro dándole forma.

Este texto es parte del mismo gesto fundante de "Mareadas en la marea", no como una Filosofía de la Historia Feminista consolidada, sino como hipótesis provisorias surgidas desde la práctica archivista y curatorial de un nosotras como forma subjetiva de lo común.

\section{Referencias}

Agamben, G. (2005). Profanaciones. Adriana Hidalgo.

Bersani, L. (2010). Is the rectum a grave? And Other Essays. University of Chicago Press.

Colectivo Ni Una Menos (2018). Amistad política + inteligencia colectiva. Documentos y manifiestos (20152018). Gráfica del Pueblo. http://niunamenos.org.ar/herramientas/biblioteca/amistad-politica-inteligenciacolectiva/

Federici, S. (2014). Calibán y la bruja. Mujeres, cuerpo y acumulación originaria. Tinta Limón.

Gago, V. (2019). La potencia feminista, o el deseo de cambiarlo todo. Tinta Limón.

Laguna, F. (2013). Control o no control. Mansalva.

Link, D. (2009). Fantasmas. Imaginación y sociedad. Eterna Cadencia.

Lopez Seoane, M. y Palmeiro, C. (2021). "Las lenguas de las locas”. El lugar sin límites. Revista de estudios y políticas de género ancilla, 3 (5), 186-192

https://revistas.untref.edu.ar/index.php/ellugar/article/view/1034

Morgan, R. (ed.). (1970). Sisterhood is Powerful. An Anthology of Writing from the Women's Liberation Movement. Random House.

Palmeiro, C. (2019a). Mareadas en la marea: archivo y vanguardia feminista. Acciones del Colectivo Ni Una Menos 2015-2019. El lugar sin límites. Revista de estudios y políticas de género ancilla, 3 (5), 1-29.

http://revistas.untref.edu.ar/index.php/ellugar/article/view/284 
Palmeiro, C. (Diciembre 2019b). Ni Una Menos: las lenguas locas, del grito colectivo a la marea global. Cuadernos de literatura, 23 (46), 177-195.

https://revistas.javeriana.edu.co/index.php/cualit/article/view/28423

Rolnik, S. (2019). Esferas de la insurrección. Notas para descolonizar el insconsciente. Tinta Limón. 